\title{
Developmental Abnormalities in a Patient with Karyotype 46,XX,Bq+
}

\author{
JOHANNA E. CHAKANOVSKIS and G. R. SUTHERLAND
}

From the Children's Cottages Training Centre, Kew, Victoria; and St. Nicholas Hospital, Carlton, Victoria, Australia

In the cytogenetic study of the mentally retarded population at the Children's Cottages Training Centre, Kew, Victoria, a 21-year-old female patient was found to have a B-group chromosome with the long arm increased in length by about $35 \%$.

\section{Case Report}

Family history. The proposita, LM300548 (II.2), is the second child of a gravida VIII, para VIII, 34year-old woman and her 30 -year-old husband. The parents are not consanguineous. The mother, a trained nurse, stated that there was no known family history of mental illness, epilepsy, or congenital deformities. Repeated attempts to locate the father were unsuccessful.

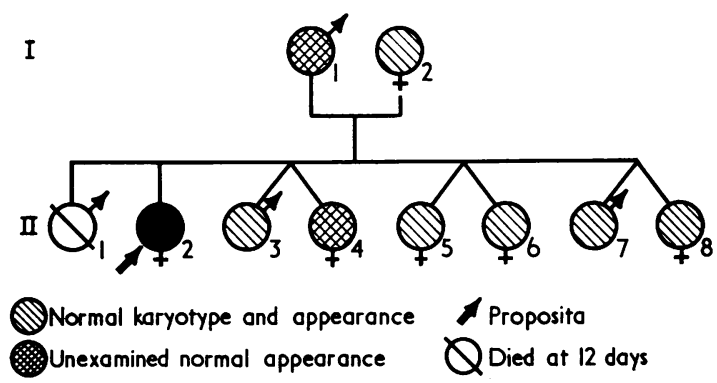

FIG. 1. Family pedigree.

The mother's first pregnancy resulted in delivery of a full-term male child, RM160647 (II.1), who died 12 days afterwards from birth trauma and anoxia. Clinically, he was said to be not malformed. Six younger sibs, who comprise three sets of dizygous twins, are phenotypically and karyotypically normal. Cases I.1 and II.4 were not available for study.

Case history. Pregnancy with the proposita was complicated by maternal toxaemia in the third trimester. Labour lasted 48 hours and resulted in a breech birth of a small, full-term, microcephalic female child. Birthweight was $2.665 \mathrm{~kg}$., head circumference was not recorded.

Received 5 January 1970.
Mental retardation was noted at the age of 6 months when she was admitted to the Royal Children's Hospital, Melbourne, with pneumonia, and, subsequently at the same hospital a general cerebral underdevelopment was diagnosed at 3 years. While at home her mother observed delay of psychomotor development. The child held up her head at 6 months, sat up alone at 2 years, stood with support at 3 years, walked at 4 years, and spoke her first words at 7 years; she fed herself at 9 years, but was not toilet trained at that time. At 7 years of age she was diagnosed as having an atypical form of congenital megacolon (Hirschsprung's disease). As the response to medical treatment was satisfactory, surgery was not performed.

At the age of 13 years the proposita was admitted to the Children's Cottages Training Centre with a diagnosis of encephalopathy of unknown origin with associated neurological signs, mild left hemiplegia, and adolescent kyphosis (Scheuermann's disease).

Clinical studies. The proposita (Fig. 2 and 3) presented as a profoundly retarded, 21-year-old girl with poor posture due to anteriorly flexed head and upper body and prominent dorsal kyphosis. Because of this, she appeared smaller than her actual height of $152 \mathrm{~cm}$. Her weight was $44.5 \mathrm{~kg}$. Apart from pronounced microcephaly (head circumference $46 \mathrm{~cm}$.) with flattened occiput, pointed vertex, and narrow bitemporal region, there was a mild plagiocephaly, with features of trigonocephaly when observed from above. Correspondingly, the forehead was narrow, extremely low (hairline-glabella distance of $3.5 \mathrm{~cm}$.), and sharply receding, with a palpable frontal bone ridge.

The hair was straight, bushy, and formed a low hairline on the forehead, with extension across the temples to the pre-auricular parts of the cheeks.

The face was slightly asymmetric and rotated around the vertical axis, with the right side displaced posteriorly. There was hypotelorism with an interpupillary distance of $5.5 \mathrm{~cm}$., and a medial intercanthal distance of $3 \mathrm{~cm}$. The left eye was slightly smaller and on a lower plane than the right. A left external strabismus was present. The pupils were contracted, the left being smaller than the right, they were round and central with minimal responses to direct and consensual stimulation. The 


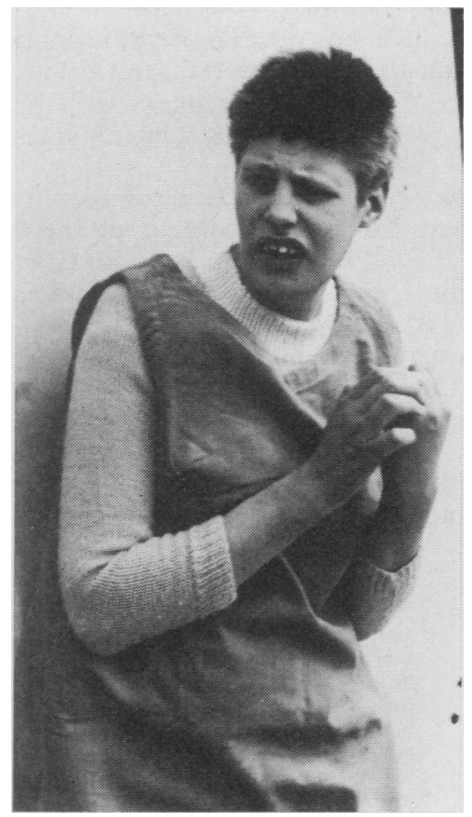

FIG. 2. Proposita (II.2). Note microcephaly, low hairline on forehead, asymmetric face, hypotelorism, prominent nose, irregular protruding upper teeth and flexion deformities of 5 th and 4 th fingers.

nose was prominent, narrow, and elongated, with the nasal septum extending beyond the alae nasi; the nostrils were almond-shaped. The upper lip appeared short, the philtrum and labial tubercle were slightly underdeveloped. The mouth was large and asymmetric, with mild depression of the right side. The alveolar margins of the maxilla protruded, and incorporated large, irregular, widely separated teeth. Underdevelopment and retraction of the mandible was associated with malocclusion and overbite. The palate was narrow, highly arched, and the tongue was fissured and bulky.

The external ears were situated close to the scalp, the helices appeared underdeveloped and the antihelices bulky and overdeveloped, especially on the left side. The lobules were adherent, and the external auditory meati appeared narrow.

The neck was slender with a low hairline posteriorly. The shoulders were rounded and there was a prominent dorsal kyphosis. Deep dimples were present over both sacro-iliac joints. Clinically the sternum was short with underdevelopment of the xyphoid process. The breasts were well developed with a 'crater-like' inversion of the central parts of the nipples. The left breast was larger than the right. The external genitals appeared slightly infantile, and there was scanty axillary and pubic hair. Menstruation was regular. Hypertrichosis was present over the limbs and over the back. Clinically the heart, lungs, and abdomen appeared normal. The blood pressure was $125 / 75 \mathrm{~mm}$. $\mathrm{Hg}$. There is now no clinical evidence of Hirschprung's disease.

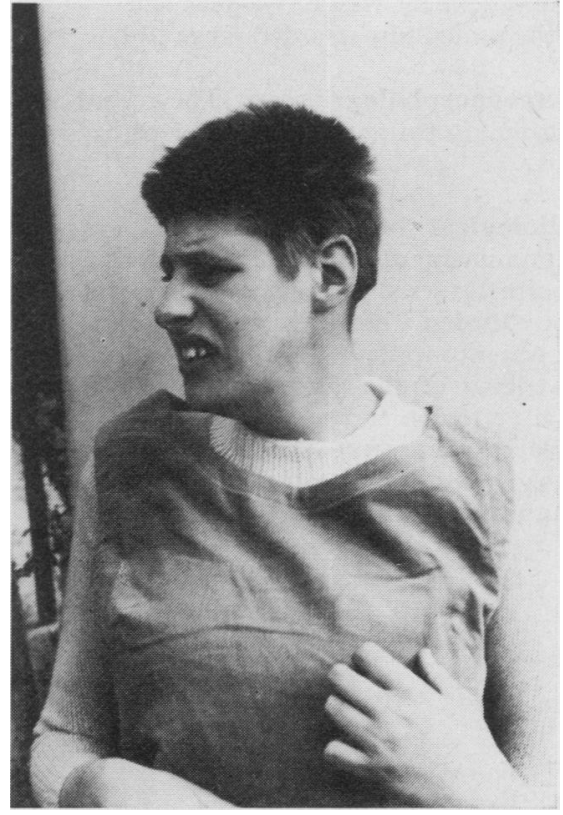

FIG. 3. Proposita (II.2). Note low hairline at the back of the neck and skin dimples over the metacarpophalangeal joints.

The extremities were long and slender, with arachnodactyly and mild acrocyanosis. The upper extremities showed the following abnormalities: cubitus valgus, hyperextensible lax joints, especially those of the thumbs, flexion deformity of both fifth and, to a lesser degree, of both fourth fingers at the proximal interphalangeal joints, ulnar deviation of the terminal phalanx of the right middle finger, and prominent skin dimples over the metacarpophalangeal joints. The anomalies of the lower limbs comprised valgoid knees, flat feet, prominent heels, large separated first toes, small fifth and fourth toes, with webbing between the second and third. Slightly hyperconvex nails were seen on all digits.

The deep tendon reflexes were normal in the upper limbs, but overactive in the lower, especially on the left side. There was a left patellar clonus, with occasional unsustained left ankle clonus and ambiguous left plantar responses.

Vision and hearing appeared intact. Ophthalmological assessment including fundoscopy revealed no abnormalities. Her gait was flat-footed and knockkneed, with dragging of the left foot when tired.

Psychometric assessment. On the Randall's Island Performance Series the proposita passed most items at a 3-4-year level, with some failures below this. Intellectually, she functioned in the profoundly retarded range (R4). Speech development was between a 3-4-year level (Binet Picture Vocabulary).

On the Vineland Social Maturity Scale she obtained scattered passes up to a 7-year level, but her over-all 
social development was at 3-4-year level. This placed her in the profoundly retarded range (R4).

Electroencephalography. The record showed no specific, and in particular no focal or paroxysmal abnormalities.

Radiological findings. The skull was small, with more prominent digital markings on the inner table, than normally seen. No intracranial calcifications were present. Evidence of a premature closure of the metopic suture was inconclusive.

A wedging of the anterior vertebral bodies of the thoracic vertebrae and narrowing of the intervertebral joint spaces was present (Scheuermann's disease). Both hands showed a flexion deformity of the proximal interphalangeal joints of fifth fingers.
Laboratory studies. Biochemical and haematological tests, including alkali resistant haemoglobin, full blood examination, Guthrie test, and urine chromatography, were all within normal limits, with the exception of a slightly raised serum gammaglobulin fraction.

Cytogenetic studies. Leucocyte cultures were prepared and harvested according to the method of Moorhead et al. (1960) and stained with Giemsa's stain. Chromosomes were counted and analysed microscopically. All non-modal cells and at least six modal cells from each individual were photographed for further analysis. Chromosome counts are shown in the Table. The proposita showed a B-group chromosome with an increase in length of the long arms of about $35 \%$ in every cell examined, including the non-modal ones, which showed random loss (Fig. 4). All family members

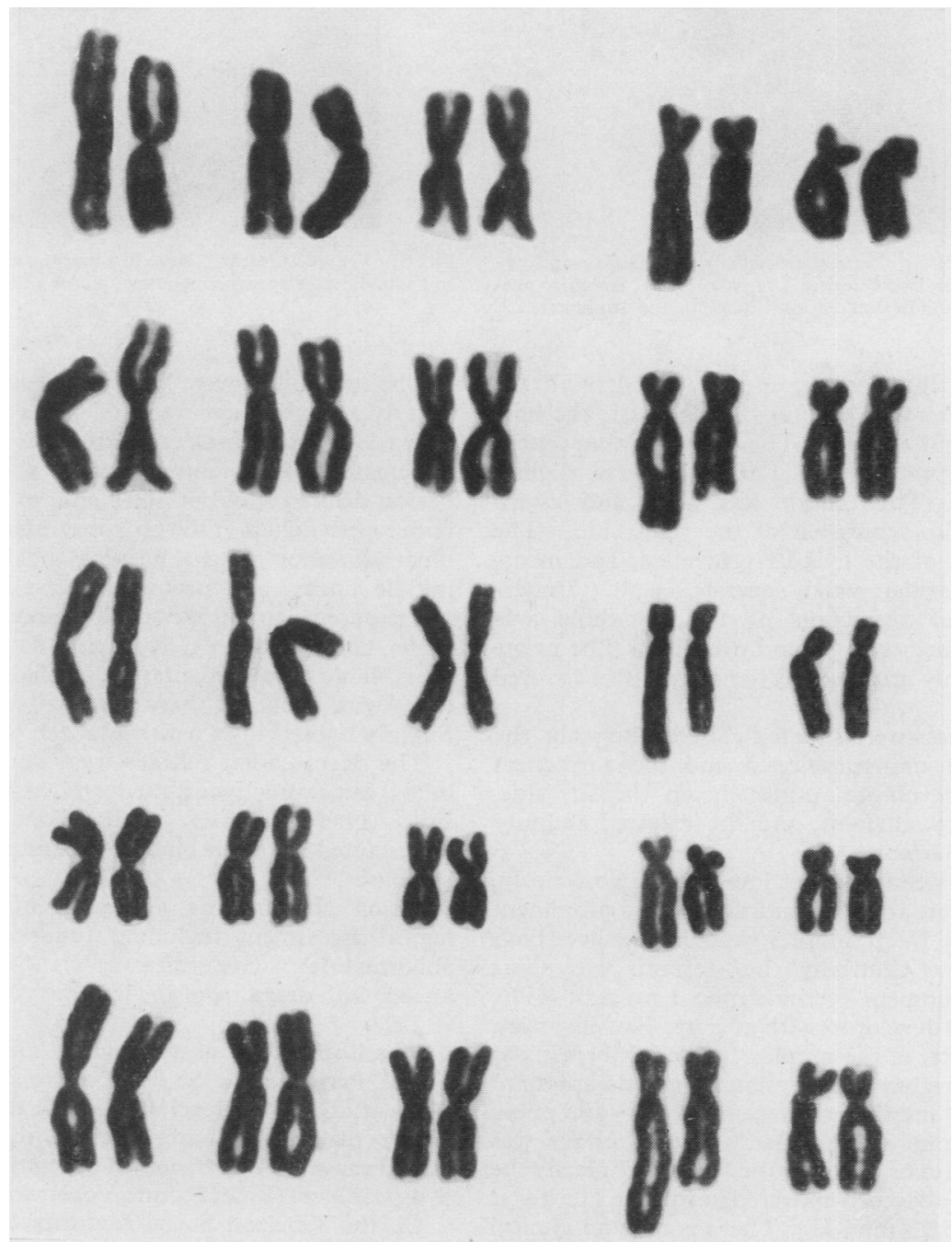

FIG. 4. A and B group chromosomes from five of the proposita's cells showing the appearance of the $\mathrm{Bq}+$ chromosome. 
TABLE

CHROMOSOME COUNTS FOR PROPOSITA AND FAMILY

\begin{tabular}{l|c|c|c|l}
\hline & 45 & 46 & Total & \multicolumn{1}{|c}{ Analysis } \\
\hline Proposita (II.2) & 9 & 51 & 60 & $46, X X, B q+$ \\
Mother (I.2) & 2 & 34 & 36 & $46, \mathbf{X X}$ \\
II.3 & 1 & 21 & 22 & $46, \mathbf{X Y}$ \\
II.5 & 1 & 20 & 21 & $46, \mathbf{X X}$ \\
JI.6 & 2 & 20 & 22 & $46, \mathbf{X X}$ \\
II.7 & 1 & 19 & 20 & $46, \mathbf{X Y}$ \\
II.8 & 2 & 19 & 21 & $46, \mathbf{X X}$ \\
\hline
\end{tabular}

studied had normal karyotypes. The proposita's buccal mucosal cells showed a normal female sex chromatin pattern. Drumsticks were normal in size and shape, and were present in $2 \cdot 5 / 100$ neutrophils.

Dermatoglyphic studies. Dermatoglyphs were essentially normal (Fig. 5). The palmar creases were unremarkable. The axial triradii were in the $t^{\prime}$ position $\left(58^{\circ}, 35 \% ; 58^{\circ}, 34 \%\right.$, right and left $)$. Thenar and hypothenar areas showed no true patterns. There were intense interdigital patterns. The $a-b$ ridge count was 46 and 58 on the right and left hands, respectively. Plantar patterns were unremarkable, with large distal loops on the hallucal areas. The Walker Index was $-2 \cdot 70$.

\section{Discussion}

An increase in the length of the long arm of a Bgroup chromosome has been reported in a number of cases over the past 7 years. Several of these have involved balanced translocations in apparently normal persons (Makino, Aya, and Sasaki, 1965; Grouchy et al., 1967; Thorburn, Smith-Read, and Peck, 1969; Court Brown et al., 1964). Some have fertility problems (Edwards et al., 1962; Mann et al., 1965) and repeated abortion (Makino et al., 1965;
Patau, 1963; Thorburn et al., 1969) attributed to their chromosomal constitution. Edwards et al. (1962) reported two sibs with congenital abnormalities with $\mathrm{Bq}+$ chromosomes inherited from their father who was a $t(B q+; \mathrm{Cp}-)$ heterozygote. Patau (1963) presented a severely retarded child with a $\mathrm{Bq}+$ chromosome whose mother and sister were $\mathrm{t}(\mathrm{Bq}+; \mathrm{Cq}-)$ heterozygotes. Thorburn et al. (1969) described an abnormal infant with a Bq + chromosome whose mother, two sisters, and maternal grandfather were $t(B q+; C q-)$ heterozygotes. Grouchy et al. (1967) reported a case of a malformed boy who had a $\mathrm{Bq}+$ chromosome resulting from maternal translocation heterozygosis; his sister carried a balanced translocation $t(\mathrm{Cp}-; \mathrm{Bq}+)$. $\mathrm{Bq}+$ chromosomes were present in a cell line in at least three cases involving mosaicism (Hsu et al., 1967; Thorburn et al., 1969; Turner, Bass, and Kaplan, 1966). There are also five reports of the spontaneous appearance of $\mathrm{Bq}+$ chromosomes (Atkins and Feingold, 1967; Bray and Ann Josephine, 1964; Gagnon et al., 1963; Gendel and Wasserman, 1966; Trujillo et al., 1966) and two additional cases in which full family studies were not possible (Iivanainen and Gripenberg, 1967; Tischler, Corey, and Co-Te, 1968). Wallace and Anderson (1964) reported a female with 45 chromosomes, who had a large $\mathrm{Bq}+$ chromosome, possibly derived from a $t(B q+; D q-)$, she showed features of Patau's syndrome.

Consideration of the dermatoglyphs gives no clue as to the origin of the extra genetic material. The Walker Index is in the zone of overlap though strongly biased towards normal (Walker, 1958). The intensity of the finger-print patterns, the
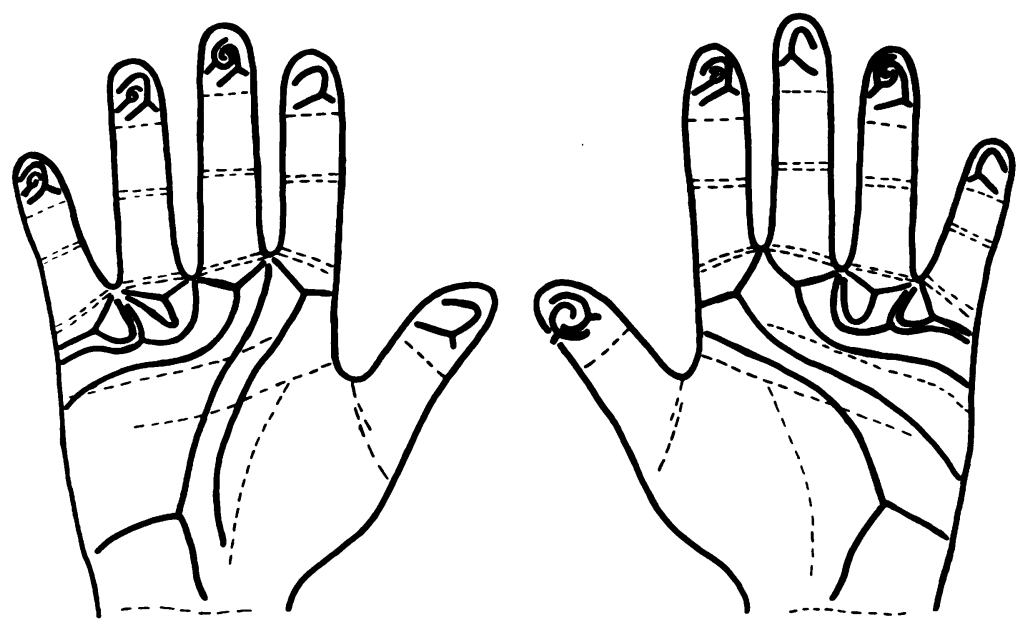

FIG. 5. Dermatoglyphic analysis of hand prints. Solid lines represent the main lines. Broken lines represent flexion creases. 
normal palmar creases, the normal position of the axial triradii, and the plantar patterns are not in keeping with either Edwards' or Patau's syndromes. The intense interdigital patterns are probably familial, as the only family member on whom it was possible to obtain prints (II.3) showed similar patterns. The over-all dermatoglyphic picture bears little resemblance to any of the published cases involving $\mathrm{Bq}+$ chromosomes.

The proposita showed a number of the clinical features seen in both $\mathrm{D}$ and $\mathrm{E}$ trisomy syndromes; however, due to the almost complete clinical overlap of these syndromes (Taylor, 1968), it is not possible to assign the extra genetic material present in the proposita to chromosomes in either of these groups.

$\mathrm{Bq}+$ chromosomes may arise either by insertion or translocation. When translocation is the mechanism involved a terminal segment of the long arm of the B-group chromosome is lost, this not being so when insertion is involved. In view of the probable multiple sources of the extra genetic material in the cases reviewed, any specific clinical similarity between them may be due to a deletion common to those cases in which the $\mathrm{Bq}+$ chromosome arose by translocation. The cases with karyotype $46, \mathrm{XX}$ (or $\mathrm{XY}$ ), $\mathrm{Bq}+$ have few common clinical features apart from the non-specific ones, such as advanced parental age, full-term gestation, with low birthweight, resuscitation, and feeding difficulties, congenital malformations and developmental and psychomotor retardation which are seen in many cases of autosomal abnormality. The only other features seen in more than half these cases were microcephaly and a single transverse palmar crease.

\section{Summary}

A case of a mentally retarded and physically handicapped 21-year-old girl having a karyotype $46, \mathrm{XX}, \mathrm{Bq}+$ is described. Detailed clinical information is provided. The origin of the aberrant chromosome is discussed but the source of the extra genetic material remains unknown.

We wish to express our gratitude to Dr. J. L. Evans and Dr. D. B. Pitt for their interest and encouragement; our sincere thanks to Dr. D. M. Danks and Dr. S. Wiener for useful suggestions and comments, and to Dr. C. G. Judge and Mr. G. Webb for critical reading of our manuscript. We thank Miss C. Zsizsmann for preparing the psychological assessment.
We are grateful to the Mental Health Authority for permission to publish this report.

\section{REFERENCES}

Atkins, L., and Feingold, M. (1967). Enlarged B-group chromosome (4-5). Association with the cri-du-chat syndrome. American Fournal of Diseases of Children, 113, 277-282.

Bray, P. F., and Sister Ann Josephine (1964). Partial autosomal trisomy and translocation; report of an infant with multiple congenital anomalies. Fournal of the American Medical Association, 187, 566-569.

Court Brown, W. M., Mantle, D. J., Buckton, K. E., and Tough, I. M. (1964). Fertility in an XY/XXY male married to a translocation heterozygote. Fournal of Medical Genetics, 1, 35-38.

Edwards, J. H., Fraccaro, M., Davies, P., and Young, R. B. (1962). Structural heterozygoses in man: analysis of two families. With a note on dermal ridge configurations, by $\mathbf{L}$. S. Penrose and S. B. Holt. Annals of Human Genetics, 26, 163-178.

Gagnon, J., Archambault, L., Laberge, E., and Katyk-Longtin, N. (1963). Trisomie partielle 18 par insertion ou translocation $4 / 18$. Union Médicale du Canada, 92, 311-319.

Gendel, E., and Wasserman, E. (1966). An asymmetric chromosome pair in group 4-5; association with mental and physical retardation. American fournal of Diseases of Children, 111, 90-95.

Grouchy, J. de, Roy, C., Lachance, R., Frezal, J., and Lamy, M. (1967). Trisomie partielle C par translocation $t(C p-; B q+)$. Archives Françaises de Pediatrie, 24, 849-858.

Hsu, L. Y. F., Nemhauser, I., Bettman, H. K., and Sobel, E. H. (1967). Mosaicism of an abnormally long B chromosome in a boy with physical and mental retardation. Pediatrics, 39, 68-74.

Iivanainen, M., and Gripenberg, U. (1967). Clinico-neurological findings in connection of three chromosomal aberrations: an extra chromosome in group E, a D/C translocation and an unusually long B-group chromosome. Acta Neurologica Scandinavica, 43, Suppl. No. 31, 53-54.

Makino, S., Aya, T., and Sasaki, M. (1965). A preliminary note on a familial B/C chromosome translocation with regard to the spontaneous abortion. Fapan Academy. Proceedings, 41, 746-750.

Mann, J. D., Valdmanis, A., Capps, S. C., and Puite, R. H. (1965). A case of primary amenorrhea with a translocation involving chromosomes of groups B and C. American fournal of Human Genetics, 17, 377-383.

Moorhead, P. S., Nowell, P. C., Mellman, W. J., Battips, D. M., and Hungerford, D. A. (1960). Chromosome preparations of leucocytes cultured from human peripheral blood. Experimental Cell Research, 20, 613-616.

Patau, K. (1963). Partial trisomy. In Second International Conference on Congenital Malformations. Papers and Discussions, pp. 5259. Edited by the International Medical Congress, New York.

Taylor, A. I. (1968). Autosomal trisomy syndrome: a detailed study of 27 cases of Edwards' syndrome and 27 cases of Patau's syndrome. Fournal of Medical Genetics, 5, 227-252.

Thorburn, M. J., Smith-Read, E. H. M., and Peck, J. E. (1969). A translocation $\mathrm{t}(\mathrm{Bq}+: \mathrm{Cq}-)$ in a West Indian family and a report of a second family showing a possible long arm group $\mathbf{B}$ translocation. Archives of Disease in Childhood, 44, 106-112.

Tischler, B., Corey, M. J., and Co-Te, P. (1968). Mental retardation in a child with a long B-group chromosome. fournal of Medical Genetics, 5, 134-136.

Trujillo, J. M., Zeller, R. S., Plessala, R. A., and List-Young, B. (1966). Translocation heterozygosis in man. American fournal of Human Genetics, 18, 215-225.

Turner, J. H., Bass, L. W., and Kaplan, S. (1966). Chromosome mosaicism in a child with features characteristic of the 'cat cry' syndrome. Fournal of Medical Genetics, 3, 66-69.

Walker, N. F. (1958). The use of dermal configurations in the diagnosis of mongolism. Pediatric Clinics of North America, 5, 531-543.

Wallace, C., and Anderson, I. F. (1964). Group B/D translocation chromosome in a case with stigmata of the D trisomy. South African Medical fournal, 38, 352-354. 